College) showed that the instability of baroclinic motion leads to a continual development of 'eddies', that is, of cyclones and anticyclones, associated with poleward and upward transfer of heat from low levels in low latitudes to high levels in the polar regions, a fundamental result of considerable importance. He also advanced a tentative explanation of the observed eddy-transport of angular momentum.

In the symposium on "Climatic Changes", Prof. K. Faegri (Bergen) pointed out the complexity of palæoclimatological evidence, the growth of trees depending on rainfall minus evaporation. He added that, while long-period variations tend to be widespread, the variations of shorter period are in genera] localized. $\mathrm{He}$ considered that the changes shown in the climate of north-western Europe since the last ice age are also shown in the climates of all other regions, in both northern and southern hemispheres. Confirmatory evidence of this was given by several other speakers.

The symposium on "Meteorology and the Community" was opened by Sir Nelson Johnson, director of the Meteorological Office, London, who described the services rendered by the Meteorological Office to a wide range of interests. Sir David Brunt, Imperial College, atter outlining some of the ways in which meteorology can help the engineer with forecasts of various kinds, suggested that there are in engineering, and in many other technologies, problems in which the meteorologist can help by applying meteorological methods to their discussion. Such services could be rendered by the individual without the backing of a large organisation. He also pleaded for a thorough survey of river flow in the British Isles. Sir William Gammie Ogg described the repercussions of meteor. ology on agriculture. He spoke of the effects of excessive rainfall on various types of soil and on the formation of soil, and referred to the effect of weather conditions on the incidence and spread of plant diseases. Other speakers agreed in finding varied interests in which meteorology can help, while N. R. Hagen (U.S.A.) thought that the private consulting meteorologist could perform a useful function.

The discussion on "Atmospheric Turbulence" was opened by Prof. P. A. Sheppard (Imperial College), who directed attention to the difficulty of defining the time-interval over which the mean value of $a$ varying quantity should be taken, and described a new instrumental method of measuring the diffusion of momentum and heat in the atmosphere. He gave a brief account of the measurements of the fluctua. tions of temperature and humidity in the lowest 10 metres over Lough Neagh, Northern Ireland, during April 1949. He was followed by H. Charnock, who elaborated the question of defining the mean value, and showed other results derived from the Lough Neagh observations. These two speakers indicated a new method of approach to the problem of diffusion by turbulence, namely, that of using specially designed instruments to obtain direct measurements of products of the momentary variations of temperature and other meteorological factors, combining these with an integrating mechanism which will yield arithmetical values for the diffusion of various entities. This indicates the possibility of a considerable advance on the days when discussion of turbulence involved the assumption of a coefficient of eddy diffusivity varying with height in accordance with some simple mathematical relation.

There was general agreement among those who attended the centenary celebrations that the symposia had been of great value in bringing out the widely differing lines of attack on the problems of meteor. ology which are being followed. It was evident that there is at the present time far greater activity in meteorological research than at any time in the past, and that while final solutions of the problems reviewed were not attained, there was evidence of definite advance in some of the most difficult problems of meteorology.

D. BRUNT

\section{METABOLIC INTERRELATIONS}

A CONTINUATION of the reports of the Con. ferences on Metabolic Aspects of Convalescence, sponsored by the Josiah Macy, Jr. Foundation, New York, has been published in a volume entitled "Metabolic Interrelations"*. The former Conferences originated as "a joint effort to do something useful for the armed services"; they have continued with a gradual swing of interest away from immediate clinical preoccupations towards more academic problems, and this swing is recognized in the change of title.

Although the statement that "Today, to be effective, medical research and practice must embrace data from all the disciplines embracing nuclear physics at one end of the spectrum and cultural anthropology at the other" and the oft-voiced plea for inter-disciplinary co-operation are entirely praiseworthy, it may be questioned whether the publication of more or less verbatim reports of impromptu discussions on ordinary papers is of much value. Re-circulation of papers and careful editing of discussions, allowing second thoughts, may indeed lead to a useful product; but questions, referring to details of technique, which could have been eliminated by more careful preparation of papers, and unanswered questions (one series ends plaintively, "What is the adrenal $N$ hormone?") serve to exasperate rather than to enlighten the reader. One feels that such discussions were probably of great value to the participants, and that such conferences do indeed further co-operation, particularly of those vitally interested in this field; but revision and publication through existing journals would be of more use to the scientific community than presentation in this semi-digested state.

The nineteen papers presented comprise seven on various aspects of bone and cartilage metabolism, one study on carbon-14 distribution after its continuous administration, two on gastric secretion, two on isotopic studies of intermediary metabolism, six on steroid metabolism (including two clinical papers on adrenocorticotrophin) and a speculative paper on intracellular energy transfer. A good deal of the material has been published elsewhere.

In the field of bone and cartilage metabolism, A. B. Gutman and T. F. Yü show that in vitro calcification of epiphysis slices is inhibited by inhibitors of glycolysis and phosphorylation when the substrate is a solution of calcium phosphate, and that the inhibition is at least partly reversed by adding glucose-1-phosphate, fructose-1,6-diphosphate or 3-phosphoglycerate. Phosphate was rapidly split from adenosinetriphosphate, but no calcification resulted.

* Metabolic Interrelations. Transactions of the First Conference, New York, February 7-8, 1949 . Edited by Dr. Edward C. Reifenstein, jun. Pp. 193. (New York: Josiah Macy, Jr. Foundation, 
R. H. Follis, jun., describes histochemical work which has mainly been published ${ }^{1}$, and with $M$. D. Levine describes a lecithinase in fœtal pig cartilage homogenates which splits lecithin. They find that neutral fat and water-soluble phosphate are formed, the latter being presumed to arise by the action of phosphatase on phosphocholine. Levine, P. S. Rubin, Follis and J. E. Howard show by means of the toluidine blue metachromatic reaction, the periodic acid - leucofuchsin reaction and the silver staining of calcium salts that the granular material deposited in subcutaneous tissue of a patient with calcinosis universalis consists of calcium salts held in a matrix identical in staining properties with calcified cartilage matrix. They also report similar studies on cartilage and bone.

The evidence of isotope work relating to exchange of calcium and phosphorus between bone salt and solution is reviewed by $H$. C. Hodge, and R. I. Lienke, G. Cullen and W. D. Armstrong describe the distribution of calcium-45 after continuous intra. peritoneal administration of ${ }^{45} \mathrm{CaCl}_{2}$ to rats. With the same technique Armstrong and S. H. Zbarsky examine the distribution of carbon-14 after giving $\mathrm{Na}_{2}{ }^{14} \mathrm{CO}_{3}$ continuously to a rat for 117 hours. Armstrong and J. Schubert" show that "the greater part of ${ }^{14} \mathrm{C}$ deposited in bone is fairly rapidly removed".

On the subject of gastric secretion, C. F. Code, C. M. Blackburn, G. B. Livermore, jun., and H. V. Ratke describe a procedure for assaying inhibition of gastric secretion in the dog, and with it have found inhibitory activity in extracts of hog gastric mucin, in human gastric juice ${ }^{3}$ and in saliva. W. B. Patterson and D. Stetten, jun., put forward the hypothesis that gastric mucosa produces a hydrogen-ion gradient by means of a stratification of the various respiratory enzymes across the cell, with dehydrogenases toward the surface and cytochrome oxidase and carbonic anhydrase toward the blood supply.

Energy transfer is considered by O. H. Schmitt, who suggests very plausibly as an alternative to highenergy phosphate bonds as carriers that energy is transferred and stored within the cell in the form of electrostatic potential gradients at interfaces. His objection to coupled reactions on the grounds that they involve multi-body collisions seems, however, rather thin, since many such reactions are known to occur at reasonable rates ${ }^{4}$.

In the discussion on intermediary metabolism, H. G. Wood shows that, on giving to fasted rats formate labelled with carbon-14 and glycine labelled with carbon-13 in the carboxyl radical, the isotope distribution in the liver glycogen formed supports the hypothesis ${ }^{5}$ that these substances form serine, which then goes to glycogen via pyruvate. Serine isolated from the liver protein also shows the expected isotope distribution. S. Gurin describes isotope experiments, with phenylalanine labelled in either the side-chain or the ring, which confirm that the side-chain shifts during metabolism and that a carbon atom from the ring becomes the $\gamma$ carbon of the acetoacetate formed. Leucine is similarly shown to form acetone and twocarbon fragments.

Finally, there are the papers on steroid metabolism. F. Albright and his collaborators show that on giving adrenocorticotrophin to patients there is a marked transitory potassium excretion, and an excessive retention of sodium suggesting its entry into cells. There is also a steady loss of nitrogen without commensurate loss of phosphorus and potassium; it is suggested that the retention of the latter is associated with glycogen retention. L. Wilkins and R. A. Lewis find that adrenocorticotrophin given to patients with Cushing's syndrome has much the same effect as in normal persons, whereas in cases of adreno-genital syndrome it causes marked sodium and chlorine loss and some loss in weight; they suggest that the adrenals may secrete a hormone causing salt loss. In another paper they discuss the effect of various testosterone derivatives on adrenal weight and cholesterol content. Methods of estimating urinary corticoid activity are compared by E. H. Venning; and D. K. Halvorsen describes the effect of sex hormones on muscle and bone tissue atrophy in the hind limbs of mice paralysed by spinal cord hemisection, and on bone total and ash weights when given throughout the life of mice. R. Pearcy

${ }^{1}$ Follis, R. H., jun., and Berthrong, M., Amer. J. Path., 24, 685 (1948). ${ }^{2}$ Schubert, J., and Armstrong, W. D., J. Biol. Chem., 177, 521 (1949). ' Brunschwig, A., et al., J. Clin. Invest., 18, 415 (1939).

-Dixon, M., "Multi-Enzyme Systems" (Cambridge University Press, 1949).

s Sakami, W., J. Biol. Chem., 176, 995 (1948).

\section{WATTLE RESEARCH INSTITUTE, SOUTH AFRICA}

$T$

HE Wattle Research Institute at Pietermaritzburg is a new Institute under three different organisations-the South African Wattle Growers Union, the University of Natal, and the Union Department of Forestry-and it has recently published a first report for 1948*. Since the work of the Institute has scarcely been begun, the publication of a report may appear to be premature; but the time is opportune to place on record details of the conception and development of the idea and its fulfilment.

The constitutional relation of the Institute to the three organisations is also of interest to study. The idea was started some time about 1937, when a number of growers, under the stimulus of discussions with the research officers of the Department of Forestry, began to take an interest in the idea of such an Institute. It was felt that the importance of the industry merited the establishment of a research organisation devoted exclusively to the improvement of wattle cultivation and tannin production and into which all the various lines of research on wattle could be gathered as a co-ordinated whole.

The opening phases of the establishment of this important Research Institute are curiously like those followed when the great Forest Research Institute at Dehra Dun, India, was first commenced in 1906-7.

As is stated in the foreword of this report, "The research programme presented is of a tentative and very fluid nature designed only to crystallize early ideas. It will be modified and extended as necessary when the various lines of work open out and take shape and as new problems become apparent." That is the way the research officers began their operations at Dehra Dun. Even during the First World War the Government of India soon recognized its great usefulness, and, before the Second World War broke out, a mighty research organisation had been built up. Let us hope that a similar record of successful expansion and progress will be the lot of the Wattle Research Institute in South Africa.

* University of Natal: Wattle Research Institute. Report for * University of Natal : Wattle Research Institute. Report for
1948. Pp. 26. (Pietermaritzburg: Wattle Research Institute, 1948.) 